\title{
O JARDIM PROIBIDO: O PESO DE VENDER PASTEL NO LUGAR ERRADO
}

José Ednilson Matos Júnior ${ }^{1}$

Marcio Roque Dos Santos Da Silva ${ }^{1}$

Felipe Borges De Santana ${ }^{1}$

Maria Elena Leon Olave ${ }^{1}$

${ }^{1}$ Programa de Pós-graduação em Administração da Universidade Federal de Sergipe - PROPADM/UFS 


\section{O JARDIM PROIBIDO: O PESO DE VENDER PASTEL NO LUGAR ERRADO}

Resumo: O presente caso de ensino conta a trajetória de sucesso de um casal de empreendedores do ramo alimentício, permeando os desafios e as conquistas enfrentados nessa jornada. A análise concentra-se no processo de expansão do negócio e no resultado gerado a partir dessa decisão, evidenciando princípios de empreendedorismo, gestão de negócios e estratégia, de modo a refletir a relevância: do cumprimento das etapas que compõem o plano de negócios, essenciais para a abertura e/ou expansão de empresas; do planejamento alinhado às necessidades organizacionais e ambientais; e da tomada de decisão gerencial.

Palavras-chave: Empreendedorismo. Gestão de Negócios. Plano de Negócios. Caso de Ensino.

\section{Introdução}

Olá! Você conhecerá agora a história de um casal de empreendedores do ramo alimentício, que atua no mercado sergipano há quase duas décadas. O texto conta a trajetória de sucesso, conquistas e desafios enfrentados na jornada empreendedora, concentrando sua análise no processo de expansão do negócio, ao investir na construção de uma loja em um shopping do interior do estado e o resultado gerado com essa decisão.

Evidencia, neste sentido, alguns princípios de empreendedorismo, negócios e algumas estratégias. A história desse casal, que começou com uma barraquinha de pastel na orla da cidade e atualmente é um empreendimento de sucesso em processo de expansão, revela características e premissas fundamentais do empreendedorismo, e que podem gerar aprendizados essenciais, contribuindo para quem está iniciando sua carreira empreendedora e também para aqueles que já estão consolidados no mercado.

O exemplo aqui posto nos faz refletir sobre a relevância do cumprimento das etapas que compõem o plano de negócios, necessárias para a abertura e/ou expansão de empresas, do planejamento alinhado às necessidades organizacionais e ambientais e da tomada de decisão gerencial.

\section{Contextualização}

\subsection{Eva e Adão no Jardim do Éden: O Princípio}

Semelhantemente à história narrada no gênesis, onde o Jardim do Éden foi construído do caos, assim também foi o início da vida empreendedora do casal Maria Silva e João Silva que, em 2011, diante das dificuldades econômicas enfrentadas, decidiram largar seus empregos formais na área do turismo para construírem o "seu jardim". O casal decidiu abrir uma barraquinha de pastel numa feirinha gastronômica localizada na orla da cidade, local privilegiado e estratégico, em meados de 2012. Inicialmente, eles contaram com as redes de contatos que tinham criado ao longo das suas trajetórias profissionais e pessoais, e aos poucos o negócio foi crescendo, as demandas foram aumentando e, consequentemente, a lucratividade, chegando a um faturamento mensal de cerca de $\mathrm{R} \$ 80.000,00$ reais. O sucesso da barraquinha de pastel levou Maria a sonhar com a abertura de uma loja física, que permitisse ampliar o 
número de atendimentos, melhorar a qualidade do produto e oferecer mais conforto e comodidade para sua clientela.

Com seu "jardim" pronto, a tarefa agora era apenas cuidar do negócio e trabalhar para a consolidação dele - o que aconteceu. O negócio deu tão certo que virou até reportagem no programa de TV Aberta intitulado "Pequenas Empresas e Grandes Negócios", o que atraiu pessoas de diversos lugares do país para conhecerem de perto sua história, o diferencial inovativo do negócio gerido pelo casal, e vivenciarem o ambiente promovido pelo empreendimento. Eles passaram a ser convidados por instituições de ensino, empresas e prefeituras do interior do estado, e até fora dele, para palestrar para outros empreendedores locais, estudantes e profissionais da área de gestão e afins. Maria se tornou uma das grandes referências de Mulher Empreendedora do Estado, ganhando vários prêmios de reconhecimento dos serviços prestados à sociedade e representando o estado em encontros regionais e nacionais de Micro e Pequenos Empreendedores (Sebrae, 2017).

Enquanto isso, o negócio ia crescendo cada vez mais, sendo que em 2015 o casal sentiu a necessidade de reformar a loja e expandir o espaço para melhor atender a sua clientela; para isso venderam até a casa própria e investiram todo o dinheiro, confiando que com o retorno sobre o investimento iriam poder comprar, posteriormente, uma casa maior e melhor.

\subsection{Eva e a Serpente: A Proposta}

Eva estava, certo dia, passeando pelo jardim, contemplando a beleza das flores e dos frutos, ouvindo o canto dos pássaros, admirando a tranquilidade dos animais se refrescando às margens do rio cristalino, e se deparou com a serpente que, de imediato, começou a conversar com ela e a lançar todo o seu encanto a fim de atraí-la.

Voltando a nossa personagem, de modo semelhante ao ocorrido com Eva, certo dia Maria estava descansando em sua casa, feliz por mais uma conquista, a reforma da sua loja, e pensando em sua trajetória vitoriosa, quando seu telefone tocou. Era a representante de um grande empreendimento comercial que estava em fase de lançamento no interior do estado. Ela gostaria de oferecer uma oportunidade para a expansão do negócio de Maria. A proposta era a abertura de uma filial num shopping de uma cidade reconhecida pela força do seu comércio local. A representante enfatizou os benefícios que surgiriam com a abertura do negócio, mas Maria não ficou convencida da proposta e falou que não possuía interesse.

Alguns dias depois, o próprio dono do empreendimento - Sr. Linhares - entrou em contato com a Maria e o João, convidando-os para uma reunião a fim de apresentá-los ao empreendimento de perto, acreditando que assim convenceria o casal a aceitar a proposta. Inicialmente, Maria apresentou resistência, porém João a convenceu de que não seria uma má ideia aceitar o convite e ir até o local para conhecer a estrutura do empreendimento.

No dia e hora marcados, o casal foi até o local sendo recepcionado pela representante do negócio (a serpente do jardim - aquela da primeira ligação) que, mais uma vez, tentou convencê-los que a proposta era um bom negócio:

- Bom dia senhores! É uma satisfação tê-los aqui e será uma satisfação maior ainda poder contar com a parceria de vocês nesse nosso novo empreendimento de sucesso! - com entusiasmo a representante os recebeu.

- Agradecemos a receptividade! - respondeu Maria. 
- Então como você sabe, recebemos uma ligação do Sr. Linhares nos convidando para vir conhecer o empreendimento e conhecermos melhor a proposta de vocês. - João continuou o diálogo.

- Isso! Isso mesmo! O Sr. Linhares não pôde estar aqui, pois precisou viajar a negócios, mas me pediu para que eu os recebesse. Como vocês podem ver, nosso empreendimento é um grande negócio que irá impactar o comércio dessa cidade e de toda a região.

- Grande mesmo! - João exclamou entusiasmado, enquanto Maria assustada observava tudo a sua volta (as máquinas trabalhando, as estruturas sendo montadas, o grande volume de material de construção) - Um campo de obra em pleno exercício de suas atividades.

- Então, Sr. João e Sr. ${ }^{a}$ Maria, temos uma proposta irresistivel para vocês! Sabemos do potencial empreendedor que possuem e da história de sucesso de vocês e, sabendo disso, queremos contribuir ainda mais com a prosperidade de vocês. - anunciou a representante, que continuou com a explanação da proposta:

- Aproveitando a força do comércio da região e considerando a recuperação ainda que tímida da economia do país, as previsões de rentabilidade do negócio são crescentes e, portanto, bastante interessantes. Além disso, nossa proposta é que vocês não tenham que pagar nada pelo espaço, apenas ficariam responsáveis pelo custo da construção estrutural da loja de vocês.

- Olha que legal! Interessante! - João reagiu positivamente à proposta feita pela representante. Maria seguiu observando silenciosamente.

- Pois é, Sr. João! Bastante interessante! Não tenho dúvidas de que esse é um negócio viável e que vocês, com a expertise e toda experiência empreendedora que possuem, farão desse empreendimento um negócio de sucesso, contribuindo também com o sucesso do nosso estabelecimento - a representante se valeu da empolgação do Sr. João e reforçou sua proposta.

- Ok! Agradecemos pela atenção! Nós vamos analisar com calma as propostas e entramos em contato, certo?! - Maria pôs fim à conversa.

Voltaram para casa e Maria continuava achando que aquela proposta não seria interessante para o momento em que estavam vivendo. $\mathrm{O}$ casal tinha acabado de concluir a expansão da loja principal e tinha investido muito nessa reforma, inclusive tinha vendido a própria casa para realizar o investimento, ou seja, não tinha capital para uma nova aplicação naquele momento.

\section{$2.3 \mathrm{O}$ fruto proibido é comido: A Aceitação}

Alguns dias depois da visita, o casal recebeu novamente a ligação do dono do empreendimento, convidando-os para uma reunião com os investidores e empreendedores do shopping. Na ocasião, Maria avisou que não poderia ir porque já tinha um compromisso e como não tinha demonstrado interesse em participar não foi ao evento. Porém, João, que pensava diferente de Maria, foi à reunião, como representante do casal.

Diferentemente do que aconteceu no Jardim do Éden, quem comeu do fruto proibido nessa história foi o homem, João, que encantado com as promessas fechou o contrato ali mesmo, voltando para casa com a novidade:

- Querida! A reunião foi excelente! Estou convencido de que esse é um bom negócio e, portanto, já fechei contrato com eles, abriremos o negócio no Shopping. - disse ele entusiasmado.

Assustada Maria respondeu: 

comigo...

- Como assim, João? Que história é essa de já ter fechado o contrato?! Você nem falou

- Mas amor, a proposta que eles apresentaram lá na reunião é muito boa! - João justificou sua decisão.

- João, não fizemos um plano de negócios... não fizemos um estudo de viabilidade, não dá para saber se esse negócio é um bom negócio. Essa decisão foi muito precipitada! - disse Maria.

- Maria, meu amor, não estamos fazendo negócio com qualquer um. Esses empreendedores já estão no mercado há muito tempo e já possuem experiências de sucesso no estado e, principalmente, na região em que atuam. Eles não entrariam em um negócio se não fosse promissor! E para um empreendimento desse porte, todos esses estudos aí que você falou já devem ter sido feitos. Vamos acreditar nas promessas que foram feitas! - João argumentou.

Pensativa, Maria respirou fundo e foi para o seu quarto. Contrato fechado e chave na mão, o que restava para ela era unir forças ao marido e encarar mais esse desafio.

A partir daí, disse Maria:

- Acabou nosso sossego!

\subsection{O Conhecimento do Bem e do Mal: As Consequências}

Assim como a decisão de comer do fruto modificou a realidade de vida do casal no Jardim, também aconteceu com o casal empreendedor ao tomar a decisão de abrir a loja no shopping do interior. Em 2016, logo após ter concluído a reforma da loja na capital, começaram a reforma do novo empreendimento.

- João, não temos mais dinheiro para investir na construção. Tudo que tínhamos, todas as nossas economias já foram investidas na reforma da loja da orla e o restante demos entrada na compra do nosso apartamento. Até nossa casa nós vendemos! - disse Maria.

- Querida, vamos ter que economizar o máximo que pudermos! Será um tempo difícil, mas é apenas por um tempo! Vamos focar no resultado que esse novo empreendimento vai nos trazer! - João, mesmo sem resposta para a problematização de Maria, buscava ser otimista.

- Economizar?! A questão não é economizar, João! Isso já estamos fazendo há algum tempo... - Maria esbravejou em tom de desespero e continuou - a questão que você não me respondeu é: de onde vamos tirar dinheiro para finalizar a construção da loja?

- Maria, calma! Vamos encontrar um jeito. - respondeu João, tentando encontrar uma solução para o problema.

- Que jeito, João?! Não quero cometer os mesmos erros que cometemos no passado. $O$ que você está pensando em fazer?! - indagou Maria.

Com a falta de capital, outros problemas foram surgindo e provocando uma série de consequências drásticas para a vitalidade do negócio.

João respondeu:

- Maria, estava refletindo aqui... temos nosso negócio na capital que graças a Deus está dando certo. Penso que nesse início podemos tirar dinheiro da matriz e investir na construção da filial, depois devolvemos... seria uma espécie de empréstimo só que entre nossas lojas, não precisaríamos envolver um terceiro nessa história.

Maria respirou fundo...

João continuou: 
- Além disso, pensei que poderíamos alugar um apartamento simples no interior, durante esse período da reforma, para facilitar a logística. Aí dividimos nosso tempo entre a capital e o interior, de modo que possamos dar assistência as duas lojas.

Reflexiva Maria comentou:

- Quanto ao aluguel do apartamento talvez seja uma boa ideia, acho que precisamos de um local, realmente, para melhor acompanharmos o andamento da reforma e até para facilitar a compra e transporte dos materiais necessários.

- Isso mesmo! - João concordou.

- Vamos ter que sangrar a loja da capital para construir a loja do interior. Isso me deixa muito preocupada, João! Já estamos prejudicando a loja central demais! Estamos tendo alguns problemas com nossos funcionários que não tínhamos antes. Alguns clientes reclamando da qualidade do atendimento e dos serviços e isso me deixa muito preocupada! lamentou Maria.

- Vai dar certo, querida! Fique calma, meu amor! É apenas no começo! Logo logo estaremos com dois empreendimentos de sucesso e esses pormenores serão ajustados! declarou João.

- Tomara mesmo, viu?! Tenho medo de que essa decisão precipitada nos cause sérios danos. - reflexiva, Maria silenciou.

Com muito esforço e com um grande acúmulo de dívidas, a loja ficou pronta, mas o shopping não. O shopping, que também estava em construção, começou a atrasar os prazos que tinham sido estipulados no contrato. E agora, Maria e João, que tinham retirado capital de um empreendimento para investir em outro, se viram de mãos atadas, pois com o empreendimento fechado não teriam como iniciar suas atividades comerciais e obter a renda que esperavam para cumprir com as obrigações assumidas na construção da nova empresa. No final de 2017, após um ano de atraso, finalmente o shopping foi inaugurado.

Como se não bastasse a demora para o início do funcionamento do shopping e as complicações financeiras advindas desse atraso, contrariando todas as expectativas apresentadas pelo grupo empreendedor, a adesão por parte da comunidade local foi aquém do esperado. No primeiro mês de lançamento, a demanda estava dentro do esperado, porém, a partir do segundo mês, a frequência de consumidores e até mesmo visitantes ao shopping diminuiu significativamente, impactando diretamente nas vendas da pastelaria, que chegou a faturar em média $\mathrm{R} \$ 90,00$ reais por dia.

À certa altura Maria indagou:

- Como manter um negócio com um quadro de 7 (sete) funcionários e todos os demais custos operacionais com um faturamento em torno de $R \$ 90,00$ reais ao dia?!

Esse era o questionamento que pairava os pensamentos dos Silva, e que passou a tirar o sono deles, uma vez que depois de todo o esforço realizado no processo de abertura da loja, eles estavam vendo o negócio indo de mal a pior. E não enxergavam perspectiva de mudança e melhoria.

E agora?! O que fazer?! 


\subsection{Fechar ou Revitalizar o Jardim: Será o fim?}

Era carnaval e para atrair clientela para sua loja, numa tentativa quase que desesperada, Maria preparou mini pastéis e foi para o shopping fazer uma ação comercial. A ideia era proporcionar aos clientes uma experiência de degustação, para que eles conhecessem a qualidade do seu produto, porém, ao chegar no estabelecimento, se deparou com um ambiente desértico e sem clientes.

Totalmente desmotivada, Maria pensou seriamente: "Qual será o futuro do meu negócio? Como eu conseguirei pagar as dívidas geradas com aquele investimento?”.

Encerrado aquele dia de trabalho, ela arrumou as coisas e voltou para sua residência reflexiva, buscando encontrar uma melhor resposta para seus questionamentos. Foi para casa decidida a ter uma conversa séria com o seu marido.

Chegando em casa encontrou seu cônjuge cabisbaixo refletindo também sobre a realidade vivenciada em seus negócios.

João disse:

- Amor, você não saiu daqui dizendo que só voltaria amanhã? - recebeu sua esposa com um abraço, assustado com o retorno precoce.

- Realmente! Mas naquela cidade eu não fico mais nenhum dia, João! - respondeu Maria emocionada.

- Calma, amor! Calma! Sei que não está nada fácil, mas precisamos manter a calma. Não é a primeira dificuldade que enfrentamos na nossa vida e não será a última. Vamos pensar com calma no que podemos fazer. - disse João, tentando acalmar Maria.

Ainda naquela noite, o casal Silva analisou com cuidado o que poderia ser feito em prol do bem-estar deles, de sua família e do negócio já em funcionamento.

- Amor! Esse negócio está afetando cada vez mais nossa saúde, nossa família e o nosso empreendimento principal, que é a loja da orla. Precisamos entender que quanto mais tempo insistirmos, maior serão as dívidas e os desgastes físicos, emocionais, psíquicos, financeiros e legais. - argumentou Maria.

O silêncio pairou no ar por alguns segundos e João, após um tempo refletindo, disse:

- Mas e se for só uma fase, amor? Se for só o tempo de adaptação?

- E você pretende esperar o tempo até quando, João?! E enquanto esperamos o tempo, vamos fazer o que? Quais são as estratégias que podemos utilizar para mudança? - interpelou Maria em tom já de desespero.

Mais uma vez o silêncio envolveu o quarto do casal e aquele diálogo se emudeceu sem uma resposta definitiva aos questionamentos que foram levantados, até pegarem no sono.

No dia seguinte, João levantou bem cedinho e decidiu fazer uma caminhada na praia, na tentativa de aliviar a tensão e buscar um pouco de paz, em meio àquela turbulência que estavam enfrentando.

Um pouco mais aliviado João retornou para casa e encontrou sua esposa na cozinha fazendo o café da manhã:

- Bom dia, querida! Dormiu bem? - perguntou João.

- Bom dia, João! Para onde foi tão cedo? - curiosa, Maria questionou.

- Acordei bem cedinho e decidi ir à praia fazer uma caminhada para aliviar os pensamentos um pouco - explicou João.

- Hum... muito bem! - aprovou a esposa. 
- Maria, estava refletindo sobre nossa conversa de ontem à noite e pensei em pedir ao contador um levantamento financeiro para sabermos nossa real situação e a partir daí tomarmos uma decisão mais sólida. O que acha? - com um semblante sereno, perguntou João.

- Excelente, amor! Apesar de temer o resultado, acho que é o melhor a se fazer agora! - Maria concordou com seu marido e juntos se sentaram para o café da manhã.

- Então vamos nessa... está vendo esse envelope aí perto de você? - João apontou para o envelope que estava na mesa e continuou - são os documentos que havia solicitado ao Pedro.

Pedro Cardoso é um profissional experiente, contador de renome na região em que atua, e assessora o casal Silva na gestão financeira e contábil de seus empreendimentos.

- Sim! Com base nos números, poderemos tomar uma decisão mais assertiva - disse Maria, abrindo o envelope.

Maria, analisando a primeira planilha, disse:

- João, estou assustada com nosso prejuízo, veja aqui! Sabia que não estávamos bem, mas está muito além daquilo que imaginava, olhe isso! - e apontou para a primeira planilha que continha a Demonstração do Resultado do Exercício (DRE) (Tabela 1).

Tabela 1 - DRE da filial da empresa aberta no shopping

\begin{tabular}{lrr}
\hline \multicolumn{3}{c}{ DRE DA EMPRESA SILVA - SHOPPING (07/2017 até 03/2018) } \\
\hline RECEITAS & $\mathbf{R} \$$ & $\mathbf{3 7 . 8 0 0 , 0 0}$ \\
(-) CUSTOS & $-\mathrm{R} \$$ & $13.230,00$ \\
(=) LUCRO BRUTO & $\mathbf{R} \$$ & $\mathbf{2 4 . 5 7 0 , 0 0}$ \\
(-) DESPESAS & $-\mathrm{R} \$$ & $649.570,00$ \\
(-) Despesas com estrutura & $-\mathrm{R} \$$ & $362.480,00$ \\
(-) Despesas com funcionários & $-\mathrm{R} \$$ & $65.590,00$ \\
(-) Despesas com equipamentos & $-\mathrm{R} \$$ & $215.000,00$ \\
(-) Despesas com aluguel do apartamento & $-\mathrm{R} \$$ & $2.100,00$ \\
(-) Despesas com água e energia elétrica & $-\mathrm{R} \$$ & $4.400,00$ \\
(=) PREJUÍzO ACUMULADO (LUCRO LÍQUIDO) $=$ & $-\mathbf{R} \$$ & $\mathbf{6 2 5 . 0 0 0 , 0 0}$ \\
\hline
\end{tabular}

Fonte: Adaptado Dados da Pesquisa (2019).

João tentou contra-argumentar:

- No começo é assim mesmo, Maria. Lembra como foi na nossa primeira loja?

Maria ressaltou:

- João, não pensei que estávamos tão ruins assim, veja o prejuízo acumulado! - disse ela assustada... e continuou - ainda tem o balanço patrimonial - e mostrou a segunda planilha (Tabela 2). 
Tabela 2 - Balanço Patrimonial da filial da empresa aberta no shopping

\begin{tabular}{|c|c|c|c|c|c|}
\hline \multicolumn{6}{|c|}{ BALANÇO PATRIMONIAL DA EMPRESA SILVA - SHOPPING (03/2018) } \\
\hline \multicolumn{3}{|l|}{ ATIVO } & \multicolumn{3}{|l|}{ PASSIVO } \\
\hline ATIVO CIRCULANTE & $-\mathbf{R} \$$ & $48.500,00$ & PASSIVO CIRCULANTE & $\mathbf{R} \$$ & $185.844,00$ \\
\hline Caixa & $\mathrm{R} \$$ & & Empréstimos & $\mathrm{R} \$$ & $169.504,00$ \\
\hline Bancos & $-R \$$ & $49.730,00$ & Salários & $\mathrm{R} \$$ & $7.496,00$ \\
\hline \multirow[t]{3}{*}{ Estoque } & $\mathrm{R} \$$ & $1.230,00$ & Água e energia elétrica & $\mathrm{R} \$$ & 624,00 \\
\hline & & & Fornecedores & $\mathrm{R} \$$ & $6.530,00$ \\
\hline & & & Tributos & $\mathrm{R} \$$ & $1.690,00$ \\
\hline $\begin{array}{l}\text { ATIVO NÃO } \\
\text { CIRCULANTE }\end{array}$ & $\mathbf{R} \$$ & $199.520,00$ & $\begin{array}{l}\text { PASSIVO NÃO } \\
\text { CIRCULANTE }\end{array}$ & $\mathbf{R} \$$ & 370.176,00 \\
\hline Móveis e utensílios & $\mathrm{R} \$$ & $41.760,00$ & Empréstimos & $\mathrm{R} \$$ & $370.176,00$ \\
\hline (-) Depreciação & $-\mathrm{R} \$$ & $3.240,00$ & PATRIMONIO LÍQUIDO & $-\mathbf{R} \$$ & $405.000,00$ \\
\hline Máquinas e equipamentos & $\mathrm{R} \$$ & $157.760,00$ & Capital social & $\mathrm{R} \$$ & $220.000,00$ \\
\hline (-) Depreciação & $-\mathrm{R} \$$ & $12.240,00$ & Prejuízo & $-\mathrm{R} \$$ & $625.000,00$ \\
\hline TOTAL DO ATIVO & $\mathbf{R} \$$ & $151.020,00$ & TOTAL DO PASSIVO & $\mathbf{R} \$$ & $151.020,00$ \\
\hline
\end{tabular}

Fonte: Adaptado Dados da Pesquisa (2019).

O casal começou a fazer ponderações sobre os primeiros resultados, e ligou para Pedro:

- Oi, Pedro, é a Maria. Bom dia!

- Olá, D. Maria! Tudo bem com a senhora? Recebeu o meu envelope? - perguntou ele.

- Recebi sim, e estou assustada, é tudo isso de prejuízo mesmo?

- D. Maria, sinto muito, esta é a situação da sua filial, é o que os números dizem - falou Pedro - a Senhora viu a folha com os índices do negócio?

- Espera aí - disse ela, e mexeu no envelope ainda mais assustada - Meu Deus?!

Pedro demonstrou pesar, mas tentou tranquilizá-la:

- Eu sei, D. Maria, sinto muito! Trabalho há tantos anos para vocês e sei que têm capacidade de recuperação, é só uma fase, muitos clientes meus estão assim também.

Maria começou a analisar os índices do negócio... (Tabela 3).

Tabela 3 - Cálculo dos índices do negócio

\begin{tabular}{l|c|r}
\hline \multicolumn{4}{c}{ ÍNDICES DE LIQUIDEZ } \\
\hline LIQUIDEZ CORRENTE & $(-\mathrm{R} \$ 48.500,00 / \mathrm{R} \$ 185.844,00)$ & $-0,26$ \\
LIQUIDEZ SECA & $(-\mathrm{R} \$ 49.730,00 / \mathrm{R} \$ 185.844,00)$ & $-0,27$ \\
LIQUIDEZ IMEDIATA & $(-\mathrm{R} \$ 49.730,00 / \mathrm{R} \$ 185.844,00)$ & $-0,27$ \\
LIQUIDEZ GERAL & $(\mathrm{R} \$ 151.020,00 / \mathrm{R} \$ 556.020,00)$ & 0,27 \\
\hline \multicolumn{2}{l}{ ÍNDICES DE ENDIVIDAMENTO } & $-0,73$ \\
\hline PART CAP TERCEIROS & {$[-\mathrm{R} \$ 405.000,00 /(\mathrm{R} \$ 185.844,00+370.176,00)]$} & 0,33 \\
COMP. DO ENDIVIDAMENTO & {$[\mathrm{R} \$ 185.844,00 /(\mathrm{R} \$ 185.844,00+370.176,00)]$} & 0,90 \\
IMOBILIZAÇÃO DO PL & $(\mathrm{R} \$ 199.520,00 / \mathrm{R} \$ 220.000,00)$ & $-4,14$ \\
\hline \multicolumn{2}{l}{ INDICES DE RENTABILIDADE } & 1,54 \\
\hline RETORNO INVESTIMENTO & $(-\mathrm{R} \$$ 625.000,00 / R \$ 151.020,00) & \\
\hline
\end{tabular}

Fonte: Adaptado Dados da Pesquisa (2019). 
Logo após, Maria respondeu:

- Eu sei, Pedro. Muitos comerciantes com os quais temos contato estão se virando como podem, mas acho que nossa situação está crítica, daqui a pouco perdemos tudo - disse ela, suando frio.

-D. Maria, gostaria que a senhora olhasse os documentos com calma, e qualquer coisa estou aqui para esclarecer as dúvidas... sei que não é uma fase fácil, mas acredite, vai passar... - Pedro falou, tentando, mais uma vez, acalmá-la.

- Obrigada, Pedro. Este final de semana será longo, gostaria de agradecer sua atenção e vou ver com João o que faremos. Obrigada pela atenção! - disse ela, encerrando a conversa e tentando manter-se otimista.

Mais tarde, Maria voltou a falar com João, e externalizou sua preocupação:

- João, nossa situação é crítica, daqui a pouco perderemos tudo se continuarmos com este negócio.

João tentou ajudá-la:

- Mas Maria, é assim mesmo! Até engrenar, teremos prejuízo... precisamos de calma neste momento - disse ele.

Por fim, sentindo-se desconfortável com a situação, como desfecho, o casal empreendedor encontrou-se diante do seguinte dilema:

Fechar ou revitalizar o jardim? Permanecer com a loja do shopping ou fechá-la? Quais os fatores que conduziram a empresa à difícil condição em que se encontra? $O$ que fazer?

\section{Notas de Ensino}

O caso de ensino explanado, ao relatar a história de vida do casal Silva, com suas premissas e nuances, oferece informações que cabem ensinamentos em algumas disciplinas e cursos. Consiste em um instrumento pedagógico valioso para os professores, uma vez que sua aplicabilidade pode proporcionar aos docentes e discentes a possibilidade de aliar os conceitos teóricos à prática, trazendo dinamicidade para sala de aula e tornando o processo de ensinoaprendizagem mais eficiente e efetivo (Roesch, 2007).

As notas de ensino são descritas a fim de sugestionar aos docentes alguns modelos de aplicação do caso de ensino, tomando como base orientações sobre: os objetivos que regem o ensino; quais as fontes e métodos de coleta das informações que compõem o caso em questão; quais as relações entre as informações contidas no caso, o objetivo de ensino e os objetivos de um curso ou disciplina; quais as disciplinas que cabem a aplicação desse caso específico; tarefas que podem ser propostas para o corpo discente; como se deve organizar e planejar a aula para o uso do caso; e conclui com sugestões de bibliografias para auxiliar o docente na fundamentação teórica da aula, como também a possibilidade de sugeri-las como leituras complementares para os alunos.

\subsection{Objetivo de Ensino}

Conceder aos alunos a possibilidade de vivenciar a relação teórico-prática em sala de aula, proporcionando aos mesmos à experimentação de situações-problema características da complexidade existente no ambiente organizacional e mercadológico. Tornando, desse modo, 
o processo de ensino-aprendizagem mais dinâmico e assertivo, ao contribuir com o desenvolvimento profissional do indivíduo nas mais diversas áreas que ele possa atuar.

\subsection{Fontes e Métodos de Coleta}

As informações que fundamentaram esse caso de ensino foram coletadas por meio de uma entrevista semiestruturada, junto ao casal de empreendedores - participantes da produção dos dados desta pesquisa. No momento, eles contaram as suas experiências durante a jornada empreendedora, relatando as conquistas, as dificuldades enfrentadas e os aprendizados colhidos durante a trajetória. Foi realizada uma visita in loco ao empreendimento do casal e, na ocasião, além da escuta ativa, foi possível observar as rotinas organizacionais e os processos internos da empresa. A entrevista foi gravada, com o consentimento dos entrevistados, a fim de obtermos informações completas e fidedignas, evitando a incompletude e até mesmo a distorção das informações transmitidas. Além disso, como fontes de dados secundárias, foram coletadas informações contidas em materiais divulgados pela imprensa, na internet e em jornais, por meio de websites e mídias sociais de empresas de jornalismo, noticiários e entretenimento.

\subsection{Relações com os Objetivos de um Curso ou Disciplina}

Considerando os princípios relatados na história apresentada, o objetivo de ensino do caso em questão, e relacionando aos objetivos que norteiam as grades curriculares de cursos e ementas de disciplinas, é possível identificar alguns aspectos que fundamentam conceitos relevantes para a aprendizagem.

No caso apresentado, identificamos atributos referentes a relevância do plano de negócios e o estudo de viabilidade, necessários para a abertura e/ou expansão de um empreendimento. Esses elementos são parte integrante de um planejamento estratégico bem elaborado e devidamente executado, que envolve a tomada de decisão gerencial estratégica, baseada na análise ambiental interna e externa à organização, sendo fundamental para a obtenção de vantagem competitiva. Todos esses aspectos podem ser tratados dentro do arcabouço teórico-prático referente ao empreendedorismo e a gestão de negócios. Além disso, também vimos questões relacionadas as características que definem o perfil do empreendedor, seja ele micro, pequeno ou médio empreendedor.

É possível também enquadrar questionamentos sobre o planejamento empreendedor e a tomada de decisão baseada em análises dos procedimentos financeiros no que condiz a natalidade e mortalidade de uma organização. Tais questões são amplamente sugeridas para os cursos de Administração, Gestão Organizacional e áreas afins.

\subsection{Disciplinas sugeridas para uso do caso}

As disciplinas sugeridas para a utilização do presente caso de ensino são: Empreendedorismo, Educação Empreendedora, Gestão de Negócios e Planejamento Estratégico.

\subsection{Fundamentação teórica}

O caso analisado propõe um modo operante à gestão de seu negócio, e traz também as proposições que revelam a importância das estratégias no que concerne a criação de um 
empreendimento e a construção e manutenção de uma vantagem competitiva no mercado. Essas vantagens são compostas por recursos e habilidades organizacionais que fazem com que possíveis competidores sejam superados no mercado (Dess, Lumpkin, Eisner, \& Mcnamara, 2016), tendo em si abrangências com relação à interdisciplinaridade ao envolver as diversas áreas funcionais, bem como estratégias organizacionais e aspectos micro e macro ambientais.

No momento em que os gestores da pastelaria buscaram expandir seus negócios, aceitando a proposta do Sr. Linhares e abrindo uma filial no shopping, resultando na não obtenção de sucesso, alguns fatores podem ser discutidos na análise desse estudo, envolvendo a estratégia e o ambiente. Mintzberg (2006) pontua que o processo estratégico, embora planejado e executado afinco, não garante a paridade com a realidade, tendo em vista a imprevisibilidade do ambiente de negócios, o que estabelece limites a capacidade de análise estratégica. Isso pode ser visualizado a partir das três estratégias de Mintzberg (2006): a estratégia pretendida resulta de decisões embasadas em análises ambientais prévias, no entanto parte dela nem sempre é implementada devido às mudanças que ocorrem no ambiente. Isso acaba gerando a estratégia emergente, fruto de novas decisões no meio do caminho. Por fim, a estratégia realizada traduz as decisões decorrentes das duas estratégias anteriores.

Para a construção de uma estratégia bem-sucedida, é necessário criar um plano e modelo de negócio. Conforme aponta Dornelas (2012), o plano de negócios é essencial para qualquer empreendedor, visto que ele fornece uma descrição minuciosa acerca do planejamento do negócio, detalhando metodicamente a oportunidade identificada. Esse plano é composto por algumas etapas que inclui: sumário executivo, plano de gestão, plano de marketing, plano tecnológico e plano financeiro. Para o Sebrae (n.d., p. 13), "o Modelo de Negócio precede a elaboração do plano de negócios [...] [o qual] descreve a lógica de criação do negócio, quer dizer, mostra que o raciocínio e a interconexão das partes fazem sentido. Nesse ponto, deverá ser muito bem explorada a questão da entrega e captura de valor".

Os empreendedores dispõem de diversas ferramentas que podem contribuir para a construção de um modelo de negócio, que auxilia no desenvolvimento das ideias de um negócio ou até mesmo na remodelagem de modelo de negócio existente. Essa ferramenta proporciona uma visão geral do negócio que engloba áreas relacionadas a clientes, oferta, infraestrutura e viabilidade financeira, contribuindo para uma análise sistêmica da organização (Osterwalder \& Pigneur, 2011).

\subsection{Possíveis tarefas a propor aos alunos}

Sabendo que esse caso de ensino pode ser utilizado como instrumento de ensino em algumas disciplinas de áreas como Empreendedorismo, Educação Empreendedora, Gestão de Negócios e Planejamento Estratégico, sugerimos aqui algumas questões direcionadas para a análise e o debate em sala de aula, além das questões já expostas no desfecho do caso, que já recomenda uma discussão e/ou reflexão.

1. A decisão tomada pelo Sr. João Silva, de fechar o contrato, foi acertada? Sim ou não? Explique os motivos que justificam a sua resposta.

2. Sendo você o dono do negócio, quais as decisões que você tomaria, estando na mesma situação que o casal Silva? Por quê?

3. O que precisa ser feito para mudar a realidade dessa empresa? 
4. Quais as principais características do perfil empreendedor do casal Silva, que contribuíram com os momentos de sucesso vividos pelo casal empreendedor, e quais características contribuíram com os percalços gerados na trajetória?

5. Como o plano de negócios poderia ter auxiliado o casal Silva na tomada de decisão sobre a expansão do seu negócio?

\subsection{Possível organização da aula para o uso do caso}

A exequibilidade do estudo do caso em sala de aula pode ser feita em grupos, onde o professor solicitará a divisão da turma em grupos com 5 (cinco) pessoas - essa quantidade pode ser ajustada de acordo com o quantitativo de alunos em classe. A divisão dos grupos pode ser coordenada tanto pelo professor, de forma aleatória, quanto por meio de uma dinâmica, como, por exemplo, a dinâmica das cores ou dos animais - onde o professor distribui entre os alunos papeletas identificando uma cor ou um animal, e ao comando do professor cada aluno tem que buscar entre os colegas quem são seus semelhantes e formar grupo. Uma vez que os grupos estiverem devidamente montados, o professor distribuirá os casos para serem lidos, discutidos e analisados em grupo. Essa discussão será norteada por um dos questionamentos, propostos pela seção anterior (Possíveis tarefas a propor aos alunos) e escolhido pelo docente, em um tempo determinado - sugerimos de 20 (vinte) a 30 (trinta) minutos para que todos consigam ler com atenção e discutir com o grupo.

Para otimizar o tempo da análise durante a aula, o professor pode solicitar a leitura prévia do caso e anotações sobre os principais pontos para os leitores. Considerando que a discussão em aula será mais proveitosa, uma vez que partirá do princípio de que todos leram com calma e fizeram suas anotações, é possível iniciar a aula lançando um questionamento para uma discussão em grupos. Discussão essa, direcionada por algum questionamento lançado pelo educador, que também estipulará o tempo necessário para a discussão, como sugerido anteriormente - a ideia aqui é trabalhar com um tempo mais curto, considerando que o caso já tenha sido antecipadamente lido. Objetivando garantir a leitura do caso por parte dos alunos, o professor pode sugerir a entrega individual dessas anotações como parte do processo avaliativo da disciplina.

O debate aberto surge como segunda etapa da atividade e pode ser norteado a partir de um outro questionamento da lista de sugestões de tarefas para os alunos. Para a condução de um debate organizado e coordenado, é recomendado que o docente, logo no início da aula, deixe as "regras do jogo" bem claras e faça isso de forma que sua turma tenha entendido e concordado com elas.

É possível ainda solicitar à elaboração de um mapa conceitual do caso proposto, como parte da análise realizada pelo alunado e a entrega ao docente, como parte integrante da avaliação da disciplina.

Como etapa final da aula, sugerimos a realização de feedbacks do docente para os discentes de modo a fazer o fechamento adequado do processo de ensino-aprendizagem, retomando às anotações feitas, ressaltando os pontos positivos que foram destacados nas análises realizadas pelos alunos, fortalecendo os ensinamentos gerados com o estudo do caso e indicando pontos de melhorias observados. Retroalimentando, dessa forma, o sistema de ensino da disciplina e gerando aprendizado. Também é importante que os estudantes tenham a oportunidade de fazerem suas avaliações e pontuarem fatores que foram interessantes nesse processo, bem como fatores que não atenderam a expectativa de ensino com qualidade. 


\section{Referências}

Dess, G. G., Lumpkin, G. T., Eisner, A. B., \& Mcnamara, G. (2016). Administração estratégica: a criação de vantagens competitivas. Rio de Janeiro: Alta Books.

Dornelas, J. C. A. (2012). Empreendedorismo. Transformando ideias em Negócios (4a ed). Rio de Janeiro: Elsevier.

Mintzberg, H., Lampel, J., Quinn, J. B., \& Ghoshal, S. (2006). O Processo da Estratégia: Conceitos, Contextos e Casos Selecionados (4a ed). Porto Alegre: Bookman.

Osterwalder, A., \& Pigneur, Y. (2011). Business Model Canvas - Inovação em Modelos de Negócios. Um Manual para Visionários, Inovadores e Revolucionários. Rio de Janeiro: Alta Books.

Roesch, S. M. A. (2007). Como escrever casos para o ensino de administração. São Paulo: Atlas.

Serviço Brasileiro de Apoio às Micro e Pequenas Empresas - SEBRAE. (2017). Pastelaria de Aracaju inova e se torna referência para moradores e turistas. Pequenas Empresas \& Grandes Negócios. Recuperado em 11 julho, 2019, de https://revistapegn.globo.com/Negocios/noticia/2017/10/pastelaria-de-aracaju-inova-e-setorna-referencia-para-moradores-e-turistas.html.

Serviço Brasileiro de Apoio às Micro e Pequenas Empresas - SEBRAE. (n.d.). Cartilha. $O$ quadro de modelo de negócios: um caminho para criar, recriar e inovar em modelos de negócios. Recuperado em 11 julho, 2019, de https://bibliotecas.sebrae.com.br/chronus/ARQUIVOS_CHRONUS/bds/bds.nsf/be606c0 9f2e9502c51b09634badd2821/\$File/4439.pdf.

\section{Sugestões de Bibliografia}

Dess, G. G., Lumpkin, G. T., Eisner, A. B., \& Mcnamara, G. (2016). Administração estratégica: a criação de vantagens competitivas. Rio de Janeiro: Alta Books.

Dornelas, J. C. A. (2012). Empreendedorismo. Transformando ideias em Negócios (4a ed). Rio de Janeiro: Elsevier.

Fidelis. A. C. F., Navaia, E. C., Tisott, P. B. A., \& Carrizo, A. M. (2017). Empreendedorismo na lógica do Effecuation versus Causation: um levantamento bibliográfico. VXII Mostra de Iniciação Cientifica, Ensino, Pesquisa e Extensão. Programa de Pós-Graduação em Administração. 
Grossi, R., \& Oliveira, J. B. (2009). As particularidades das pequenas empresas sob a ótica do empreendedorismo e da teoria do processo de formação das estratégias. São Paulo: ENANPAD.

Lopes, R. M. A (Org.). (2010). Educação Empreendedora: conceitos, modelos e práticas. Rio de Janeiro: Elsevier; São Paulo: SEBRAE.

Ludicibus. S. (2017). Análise de Balanços (11a ed). São Paulo: Atlas.

Mintzberg, H., Lampel, J., Quinn, J. B., \& Ghoshal, S. (2006). O Processo da Estratégia: Conceitos, Contextos e Casos Selecionados (4a ed). Porto Alegre: Bookman.

Oliveira, D. P. R. (2018). Planejamento Estratégico: conceitos, metodologias, práticas (34a ed). São Paulo: Atlas.

Rosa, C. A. (2007). Como elaborar um plano de negócio. Brasília: SEBRAE.

Santiago, E. G. (2009). Vertentes Teóricas Sobre Empreendedorismo Em Shumpeter, Weber E Mcclelland: Novas Referências para a Sociologia do Trabalho. Revista de Ciências Sociais, v. 40, n. 2, p. $87-103$.

Serviço Brasileiro de Apoio às Micro e Pequenas Empresas - SEBRAE. (n.d.). Cartilha. $O$ quadro de modelo de negócios: um caminho para criar, recriar e inovar em modelos de negócios. Recuperado em 11 julho, 2019, de https://bibliotecas.sebrae.com.br/chronus/ARQUIVOS_CHRONUS/bds/bds.nsf/be606c0 9f2e9502c51b09634badd2821/\$File/4439.pdf.

Silva. J. P. (2006). Análises Financeiras das Empresas ( $8^{a}$ ed.). São Paulo: Atlas.

Verga, E., \& Silva, L. F. S. (2014). Empreendedorismo: evolução histórica, definições e abordagens. Revista de Empreendedorismo e Gestão de Pequenas Empresas, v. 3, n. 3, p. 3-30. 